\title{
TERRESTRIAL LASER SCANNER AND FAST CHARACTERIZATION OF SUPERFICIAL LESIONS IN ARCHITECTURAL DIAGNOSIS
}

\author{
A. Costa-Jover ${ }^{a^{*}}$, S. Coll-Pla ${ }^{\text {a }}$ J. Queral Llaberia ${ }^{\text {a }}$ D. Moreno García ${ }^{a}$, A. Gas Llatge ${ }^{a}$

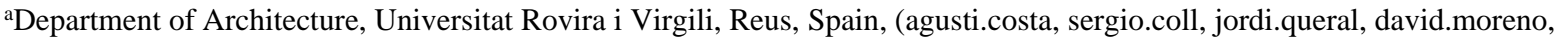 \\ albert.gas)@urv.cat
}

\section{Comission II}

KEY WORDS: terrestrial laser scanner, pathology, defensive towers, masonry, Camarles Tower.

\begin{abstract}
:
The development of massive data captures techniques (MDC) in recent years, such as the Terrestrial Laser Scanner (TLS), raises the possibility of developing new assessment procedures for architectural heritage. The 3D models that it is able to obtain is a great potential tool, both for conservation purposes and for historical and architectural studies. The paper proposes a simple, non-invasive methodology for the assessment of masonry vaults from point clouds which makes it possible to obtain relevant data about the formal anomalies. The methodology is tested in Tortosa's Gothic Cathedral's vaults, where the geometrical differences between vaults, a priori equal, are identified and related with the partially known construction phases. The procedure can be easily used on any other vaulted construction of any kind, but is especially useful to deal with the complex geometry of Gothic masonry vaults.
\end{abstract}

\section{INTRODUCTION}

International conservation institutions and restoration specialists recommend undertaking surveys accurately and rigorously for the preservation of architectural heritage (UNESCO, 1965), (ICOMOS, 1996), (ICOMOS, 2003). Current documentation procedures are very varied, and the use of massive data capture techniques (MDCT), such as terrestrial laser scanning and digital photogrammetry, have become widespread during the last decade, since they allow to obtain highly accurate topographic surveys in a short period of time (Pavlidis et al., 2007), (Yastikli, 2007). In addition, the recent years' technical development has allowed cost reduction (Lerones, Fernández, Gil, Gómez-García-Bermejo, \& Casanova, 2010). Numerous investigations have tested the techniques' reliability on and proved their effectiveness and compatibility to obtain high precision topographical documentation (Grussenmeyer et al., 2008), (Pandžić et al., 2017).

These techniques are very useful in historical constructions, since the architecture is complex and irregular, and many elements, such as vaults and domes, are not accessible. Thus, many investigation deal with the use of that techniques to survey heritage buildings (Fassi et al., 2011), (Martínez et al., 2013).

Currently, many research lines that deal with heritage are based on MDCT surveys, such as the developing of hBIM applications (Heritage Building Information Modeling) (Fryskowska and Stachelek, 2018) or monitoring procedures (Masciotta et al., 2017) are an important areas of research.

In the specific field of construction diagnosis, the use of these techniques have great potential in tasks such as the detection of displacements, (Oskouie et al., 2016), assessing materials properties (Suchocki and Katzer, 2016), or detecting cracks (Laefer et al., 2014). In addition, stone degradation processes are a large research area in the field of construction pathology, and it is possible to find numerous and varied investigations that goes from the assessment of degradation processes (Gisbert Aguilar et al., 2018) to new applications of photogrammetry for the evaluation of restoration techniques (López-Martínez et al.,
2018), among many others. Moreover, both terrestrial laser scanner and photogrammetry are used for the assessment of the state of conservation of a building and the detection of pathological processes (Sidiropoulos et al., 2017), (Del Pozo et al., 2015), (Sánchez-Aparicio et al., 2015).

The assessment of geometrical deformations is essential in architectural heritage conservation. Many studies have developed simple procedures using the point cloud data, to address deformation of ancient structures, such as the Cathedral of Tortosa (Costa-Jover et al., 2017), the church of Santa Maria of Portonovo (Quagliarini et al., 2016), the Cantalovo church (Bonali et al., 2014), and the Palazzo d'Accursio (Pesci et al., 2012) among others.

The communication focuses on the application of massive data capture techniques and geometrical assessment applied to the field of diagnosis for construction. The aim of the research is to present an easy and fast procedure to analyse the surface of a stone masonry building, a medieval Tower located in Camarles (South of Catalunya). Due to the observed degradation processes, the procedure intentionally omits considerations about material, focusing on the geometrical variations from a surface of reference (standard primitive) which allow detecting irregularities over the surface, which are related to degradation processes.

\section{CASE STUDY: THE CAMARLES TOWER}

The case studied is a medieval Tower located in the town of Camarles (Figure 1), in the South of Catalunya (Spain). It was built over an Islamic defensive fortification between thirteenth and fourteenth centuries. It has circular floor plan and a massive structure of stone masonry which was surrounded by other buildings until de decade of $80 \mathrm{~s}$, when it was performed a restoration process which involved the removal of these structures and the adaptation of the tower for visitors.

The tower is one of the most remarkable medieval defensive constructions of the Delta de l'Ebre, an area which still 
preserves a relevant number of look-out medieval towers. The tower is in good condition on general terms, and does not present structural problems that can affect the stability, but several degradation processes are visible on the surface.

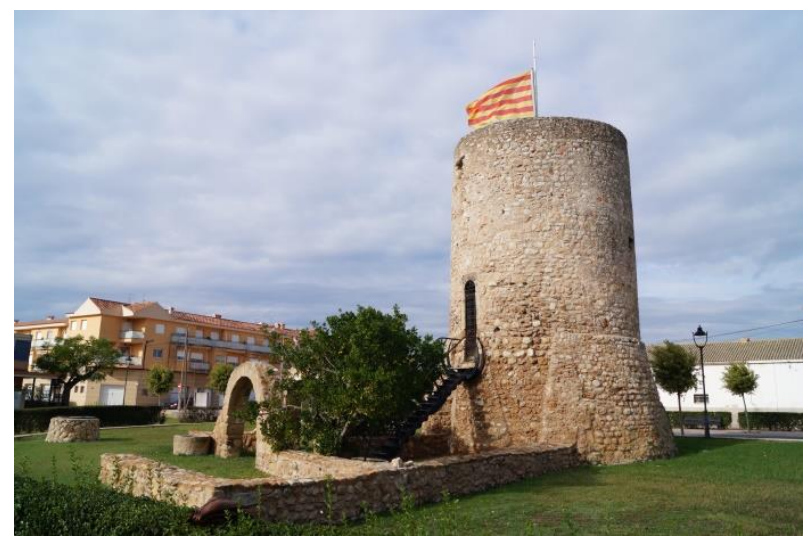

Figure 1. The Tower of Camarles

On general terms, the tower consists on a cylindrical body and a conical base of $3.9 \mathrm{~m}$ high, with a circumference radius of 4.21 in the lowest part, and 3.22 in the highest part, where meets with the cylindrical body, with a total height of $9.5 \mathrm{~m}$ and an average radius of $3.22 \mathrm{~m}$.

The access to the interior of the tower takes place through a narrow door located at a height of $3.05 \mathrm{~m}$, which gives access to a chamber with a metallic spiral staircase that communicates with the top of the tower. The inner space floor is located at a height of $4.25 \mathrm{~m}$, and has an average radius of $1.7 \mathrm{~m}$. The average thickness of the walls is $1.52 \mathrm{~m}$. This chamber is covered by a masonry dome with a central circular orifice which gives access to the upper level.

Surrounding the tower it can be found the medieval remains of old structures that were attached to the tower, which were removed on 1992.

\section{METHODOLOGY}

The methodology of the investigation proposes the use of simple procedures to assess the superficial alterations of the Tower, based on a TLS survey. The study avoids considerations about material properties, and it is mainly focused on geometrical information.

The scanner used in that case is a BLK Leica device, which is a very compact model (it weighs less than $1 \mathrm{Kg}$ ) that allows a very simple and fast surveying process, since it is not necessary to register reference points neither to plumb the device. The main technical features are that it registers 360.000 points/second with a precision of $4 \mathrm{~mm}$ at $60 \mathrm{~m}$, and the incorporated camera allows obtaining a complete survey (points and photographs) in 3 minutes.

Despite other devices have better technical characteristics than in terms of range and density of points, the lightness and ease of use makes this device a very good option for architectural surveys, especially in cases with short distances and high compartmentalisation. The survey was focused on the external walls of the tower, were the main lesions and degradation processes can be found.
After the registration process in the field, the software Cyclone 360 was used to register the point clouds in the same local coordinate system with $0.0135 \mathrm{~mm}$ of alignment error between all the registrations. 22 registrations were needed to complete the topography of the object.

The assessment of the shape of the external wall was performed through different procedures with the program 3D Reshaper. The representation of the information obtained is shown with different visualizations of the Tower wall unfolded elevation.

First, the structure was divided in two parts: the conical base and the cylindrical body (2.639.866 points and 4.742 .608 points respectively), and the corresponding closest standard primitives were defined for each one. It must be taken into account that the results of an analysis of a real object regarding standard primitives needs interpretation. It is recommended to contrast the results with complementary information to define the conclusions of the study. Following, the centroid of every primitive shape (cone and cylinder) (Figure 2) was obtained. Finally, it was defined a common vertical vertex through the two primitives' centroids to obtain an unfolded elevation of the tower.

Complementarily to the TLS survey, it is performed a photogrammetric (Structure From Motion) survey with informative purposes. 208 photographs of the exterior were, 160 for the interior and 120 for the roof. After that, the photographs were processed with the software Agisoft Photoscan. A point cloud of 47.294.407 points was obtained, and a model with a mesh of 1.419 .029 faces and 715.902 vertexes. The textured mesh was uploaded to Sketchfab (https://skfb.ly/6EEVM).

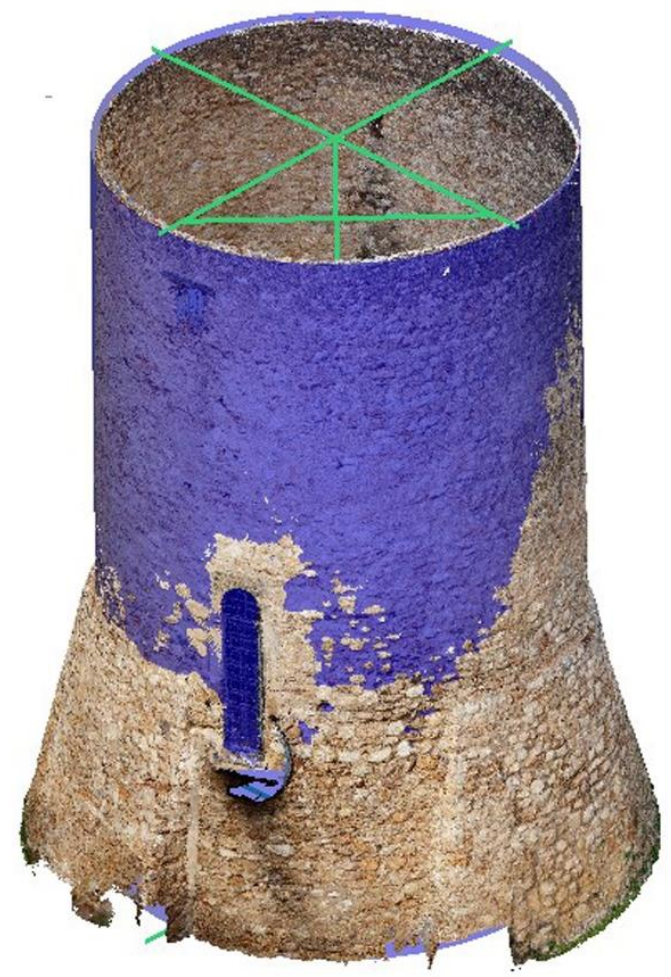

Figure 2. Visualization of the point cloud of the Tower with the standard primitives and the deduction of the central vertex. 


\section{RESULTS}

According to the initial visual inspection of the Tower, the main lesions identified in the masonry structure are: humidity along the conical base (internal and external at different heights), presence of dirt along of exterior facade; presence of plants and mosses; and erosion and loss of material on several areas. The study performed makes it possible to identify and represent this areas, as well as verify formal deviations of the Tower, regarding verticality and other formal anomalies.

The assessment of the surface is performed through different documents. First of all, the unfolded elevation of the textured surface with a known scale, gives a valuable survey of the tower, which allows visualizing clearly on a single image the different degradation processes as loss of material and other superficial issues (Figure 3a). Of course, this image is descriptive, not analytic, and needs interpretation.

Following, it is defined an Inspection visualization of the elevation. The 3D Reshaper command allows inspecting the slopes of a mesh or a point cloud (on that case, a point cloud). An inspection value will be associated to each point of the cloud or vertex according to the angle between the local normal of the surface and the horizontal. The view obtained highlights differential areas were the materials (mainly the lime mortar), are eroded or dirty (Figure 3b). These elevations allow the easy detection of eroded areas, which are represented through Autocad (Figure 3c).
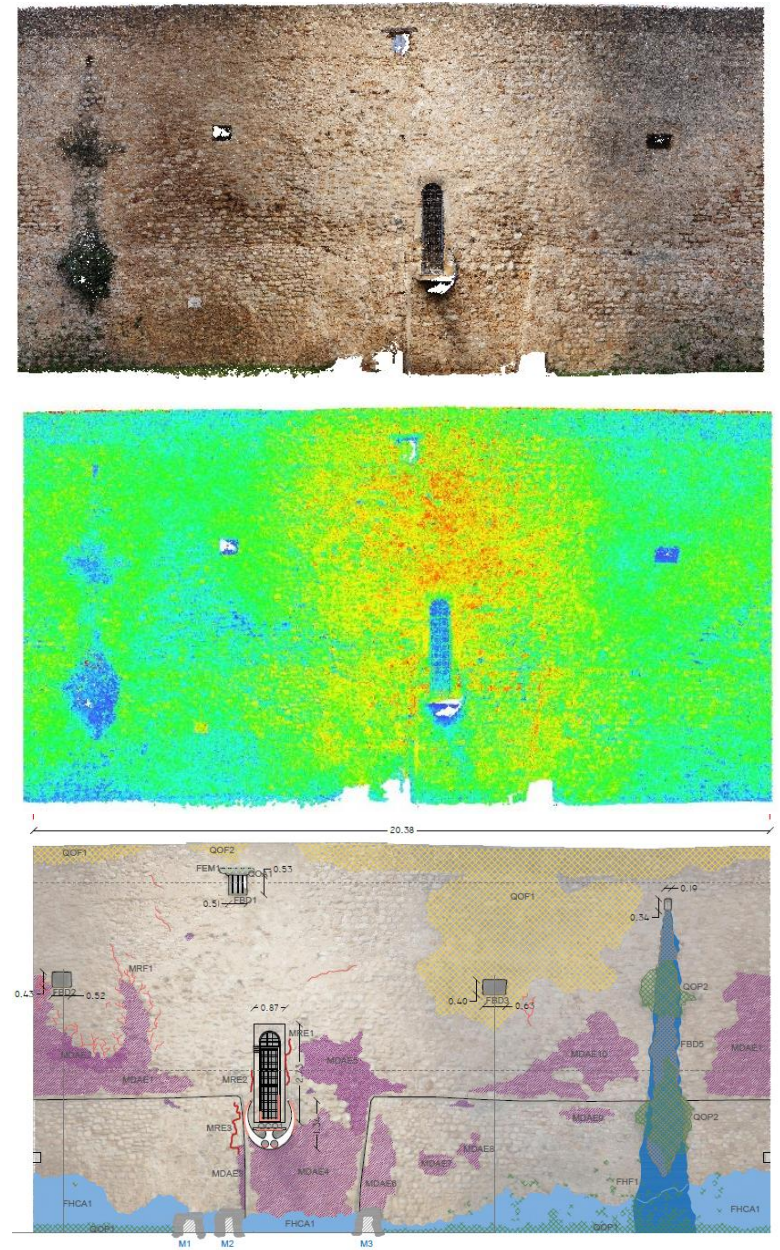

Figure 3. Unfolded elevation of the Tower's surface. a) Texture, b) Inspection map, c) Lesions identification.
The analysis of the tower shape is performed by the comparison of the point cloud and standard primitives (Table 1). It gives a general view of the irregularities and the areas which are out of plumb. At the cone we obtain a $0.105 \mathrm{~mm}$ of standard deviation, meanwhile, in the cylinder this value is $0.0402 \mathrm{~mm}$ (Figure 4).

Table 1. Dimensional values of the standard primitives.

\begin{tabular}{lcc} 
& CYLINDER & CONE \\
\hline Center & $0.67,17.81,-2.25$ & $0.71,17.72,-2.23$ \\
Radius & 3.32 & $4.12,3.21$ \\
Length & 10.5 & 3.88 \\
Angle & - & 13.15 \\
Perpendicular axis & $0.02,0.007,0.99$ & $0.006,0.008,0.99$ \\
Area & 221.20 & 91.94 \\
Limit frame min. & $-2.64,14.49-2.32$ & $-3.40,13.60,-2.28$ \\
Limit frame max. & $4.21,21.21,8.39$ & $4.84,21.84,1.68$
\end{tabular}
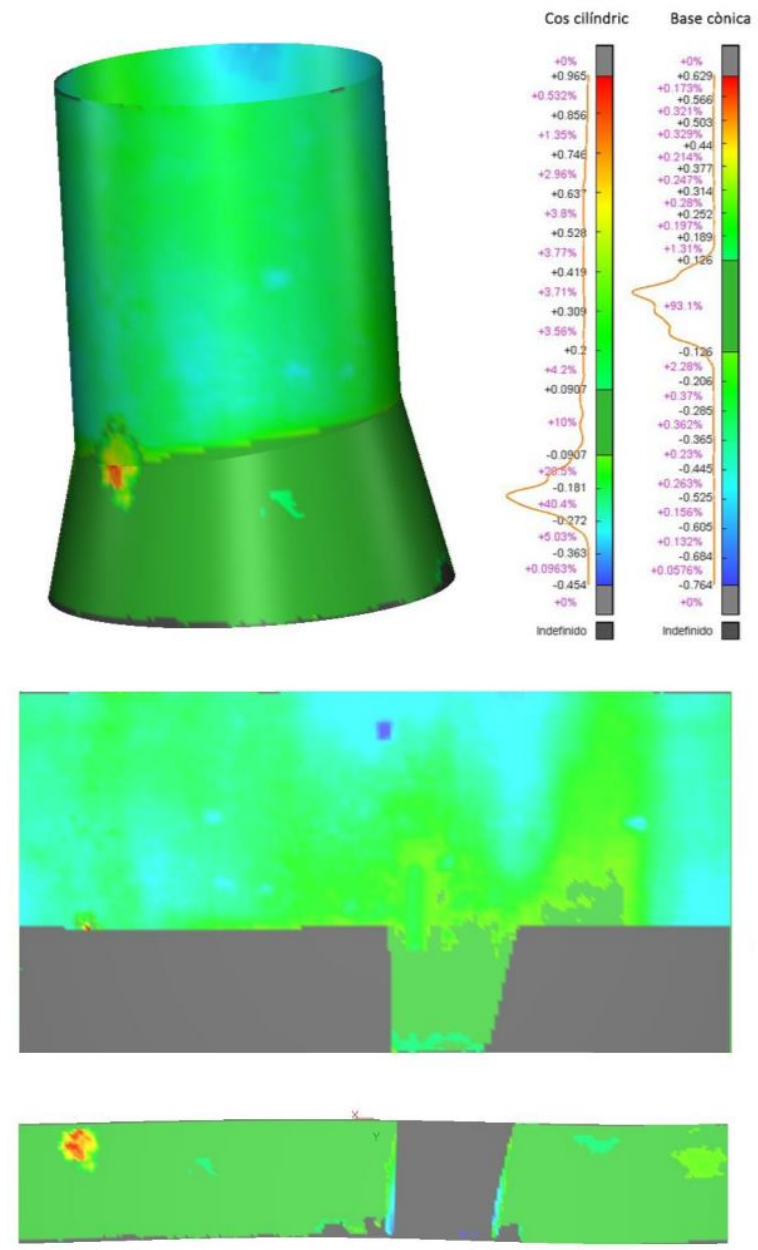

Figure 4. Scalar map of distances between Tower point cloud and standard primitives.

In the case of the conic base, most of the percentage of points are irrelevant, since the $(93.10 \%)$ of points are located at a range of $( \pm 0.126 \mathrm{~mm})$, which means that the shape of the base is very regular and close to a perfect cone. In the case of the cylindrical body, the main range of distances is $[-0.181 ;-0.272]$ with a $(40.40 \%)$ of points (Figure 5). 

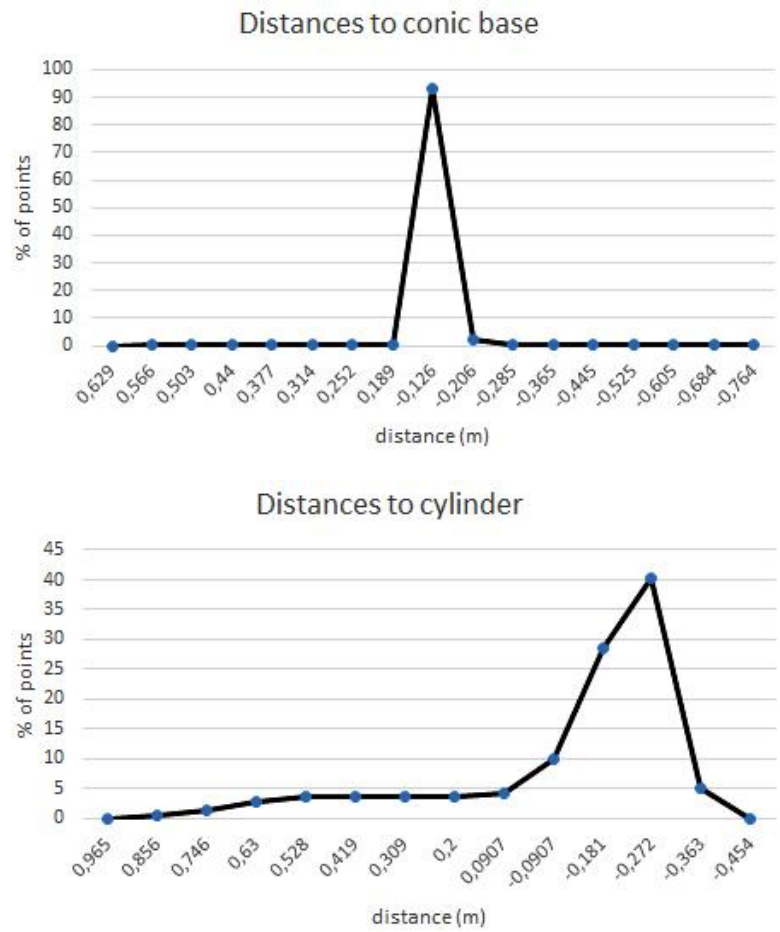

Figure 5. Summary of the histograms for the comparison with standard primitives.

In addition, the unfolded elevation is compared with a plane of reference, located in the lower left corner of the entrance door, in order to verify the verticality of the walls all over the surface (Figure 6). Results shows that predominant range of distances I $[-0.0045 ;-0.19](55 \%)$ (Figure 7).

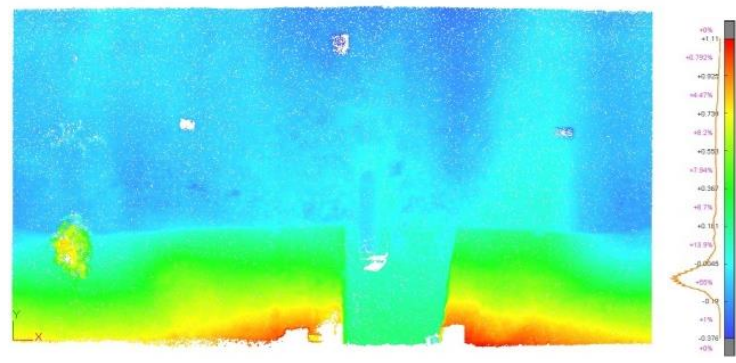

Figure 6. Scalar map of distances between Tower and vertical plane of reference.

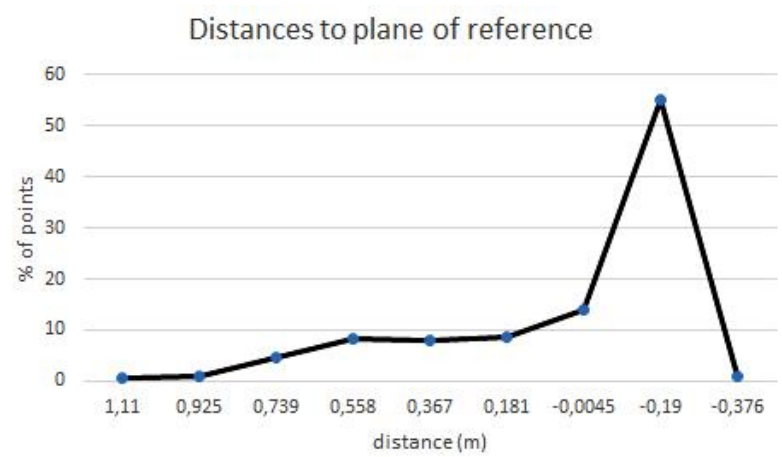

Figure 7. Summary of the histogram for the comparison with a comparison vertical plane.
Complementary, a cross section is laid out to verify previous results and to visualize the deviation of the wall on a specific cross line (Figure 8). The section plane is defined as the normal plane to the door opening (cutting through the middle of the door). It shows that the tower tend to shrink on its upper part. The main movements are located on the top are $(0.21 \mathrm{~m})$ and $(0.15 \mathrm{~m})$, with angles of $1.74^{\circ}$ and $1.02^{\circ}$ respectively.

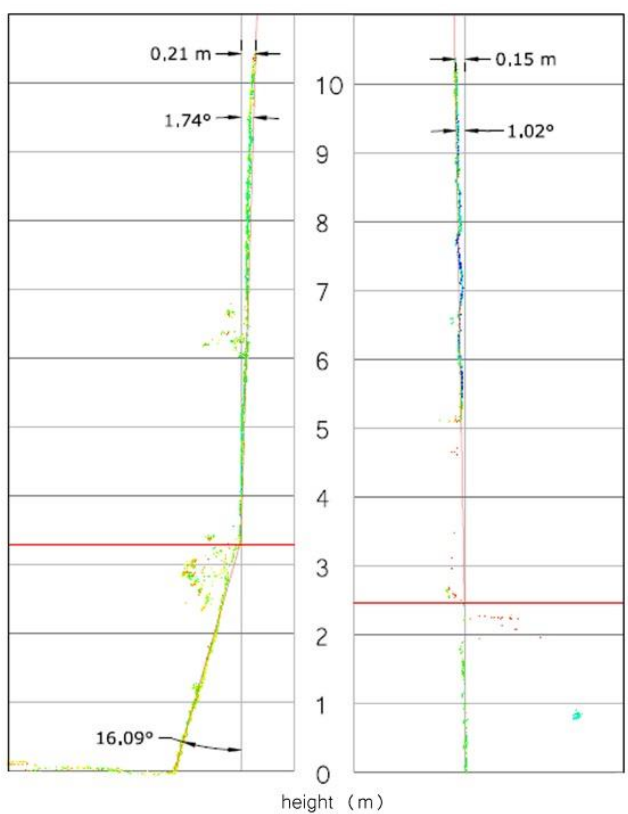

Figure 8. Points of the cross section.

\section{DISCUSSION AND CONCLUSIONS}

The investigation has tested the use of simple procedures, based on a TLS survey, to analyse the state of conservation of a masonry wall, focusing on the external surface. Some of the damages were clearly visible, but the new information allows identifying and quantifying those areas on a fast, easy and contactless way. Further research will investigate the quantification of the loss of material, regarding both holes depth and volume of lost material. In addition, these procedures have been performed "manually", so further research will also test the automation of the processes.

The textured unfolded elevation allows representing the complete surface of the Tower on a single image with metric scale. The Inspection map complements the information, and highlights the different textures that can be identified on the wall. Based on these two documents, it is easy to identify and accurately draw the main issues related to erosion, dirt and also changes on the lime mortar (qualitatively), since several restorations are overlapped on the wall. Further research on that sense will deepen on the automation of that process, and also on the use of other data from the survey, as reflectance maps.

Regarding 3D formal assessment, these aims verify the flatness and verticality of the Tower walls. The assessment from standard primitives shows the main formal differences between the Tower shape and the ideal shape of reference. It involves both vertical and floor plan so the results need interpretation since probably most of them can be related more to deviations during the construction (or restoration) processes than to stability problems. On that sense, the comparison with a vertical 
plane of reference complements the information, and qualitatively there are no relevant changes between that two approximations. It is remarkable that the inspection map gives more detail over little changes on the surface.

On conclusion, the procedures tested has allowed to easily characterise the degradation processes of the external wall of the Tower, specially related to dirt and erosion (which were visible and now are accurately quantified) and formal deviations (which were not visible considering that no evident problems were noticed). Further research will focus on automatization of procedures and test of other useful data that can be obtained from TLS for diagnosis.

\section{References}

Bonali, E., Pesci, A., Casula, G., Boschi, E., 2014. Deformation of Ancient Buildings inferred by Terrestrial Laser Scanning methodology: the Cantalovo church case study (Northern Italy). Archaeometry (56), pp. 703-716.

Costa-Jover, A., Lluis Ginovart, J., Coll-Pla, S., López Piquer, M., Samper-Sosa, A., Moreno García, D., Solís Lorenzo, A.M., 2017. 3D surveying and geometric assessment of a gothic nave vaulting from point clouds. Int. Arch. Photogramm. Remote Sens. Spat. Inf. Sci. - ISPRS Arch. 42, pp. 203-208.

Del Pozo, S., Herrero-Pascual, J., Felipe-García, B., Hernández-López, D., Rodríguez-Gonzálvez, P., GonzálezAguilera, D., 2015. Multi-sensor radiometric study to detect pathologies in historical buildings. Int. Arch. Photogramm. Remote Sens. Spat. Inf. Sci. - ISPRS Arch. 40, pp. 193-200.

Fassi, F., Achille, C., Fregonese, L., 2011. Surveying and modelling the main spire of Milan Cathedral using multiple data sources. Photogrammetric Record (26), pp. 462-487.

Fryskowska, A., Stachelek, J., 2018. A no-reference method of geometric content quality analysis of 3D models generated from laser scanning point clouds for hBIM. Journal of Cultural Heritage (34), 95-108.

Gisbert Aguilar, J., Buj Fandos, O., Bauluz Lázaro, B., Peddis, F., Cuccuru, F., 2018. Deterioration caused by dimensional change in stone (EBD pathology): the role of the organic matter - pore network - salt combination. Journal of Cultural Heritage (34), pp. 198-207.

Grussenmeyer, P., Landes, T., Voegtle, T., Ringle, K., 2008. Comparison methods of terrestrial laser scanning, photogrammetry and tacheometry data for recording of cultural heritage buildings. Int. Arch. Photogramm. Remote Sens. Spat. Inf. Sci. 37 (B5), pp. 213-218.

ICOMOS, 2003. Principios para el análisis, conservación y restauración de las estructuras del aptrimonio arquitectónico.

ICOMOS, 1996. Principles for the recording of monuments, groups of buildings and sites, in: 11th ICOMOS General Assembly. Sofia.

Laefer, D.F., Truong-Hong, L., Carr, H., Singh, M., 2014. Crack detection limits in unit based masonry with terrestrial laser scanning. NDT\&E International (62), pp. 66-76.

López-Martínez, T., García-Bueno, A., Medina-Flórez, V.J., 2018. New methodology for the assessment of cleaning treatments. Applications of photogrammetry for restoration.
Journal of Cultural Heritage (30), pp. 117-123.

Martínez, S., Ortiz, J., Gil, M.L., Rego, M.T., 2013. Recording Complex Structures Using Close Range Photogrammetry: The Cathedral of Santiago De Compostela. Photogrammetric Record (28), pp. 375-395.

Masciotta, M.G., Ramos, L.F., Lourenço, P.B., 2017. The importance of structural monitoring as a diagnosis and control tool in the restoration process of heritage structures: A case study in Portugal. Journal of Cultural Heritage (27), pp. 36-47.

Oskouie, P., Becerik-Gerber, B., Soibelman, L., 2016. Automated measurement of highway retaining wall displacements using terrestrial laser scanners. Automation in Construction (65), pp. 86-101.

Pandžić, J., Pejić, M., Božić, B., Erić, V., 2017. Error model of direct georeferencing procedure of terrestrial laser scanning. Automation in Construction (78), pp. 13-23.

Pavlidis, G., Koutsoudis, A., Fotis, A., Vassilios, T., Christodoulos, C., 2007. Methods for 3D digitization of Cultural Heritage. Journal of Cultural Heritage (8), pp. 93-98.

Pesci, A., Bonali, E., Galli, C., Boschi, E., 2012. Laser scanning and digital imaging for the investigation of an ancient building: Palazzo d'Accursio study case (Bologna, Italy). Journal of Cultural Heritage (13), pp. 215-220.

Quagliarini, E., Clini, P., Ripanti, M., 2016. Fast, low cost and safe methodology for the assessment of the state of conservation of historical buildings from 3D laser scanning: The case study of Santa Maria in Portonovo (Italy). Journal of Cultural Heritage (24), pp. 175-183

Sánchez-Aparicio, L.J., Villarino, A., García-Gago, J., González-Aguilera, D., 2015. Non-contact photogrammetric methodology to evaluate the structural health of historical constructions. Int. Arch. Photogramm. Remote Sens. Spat. Inf. Sci. - ISPRS Arch. 40, pp. 331-338.

Sidiropoulos, A.A., Lakakis, K.N., Mouza, V.K., 2017. Localization of pathology on complex architecture building surfaces. Int. Arch. Photogramm. Remote Sens. Spat. Inf. Sci. ISPRS Arch. 42, pp. 617-621.

Suchocki, C., Katzer, J., 2016. An example of harnessing Terrestrial Laser Scanner for remote sensing of saturation of chosen building materials. Construction and Building Materials (122), pp. 400-405.

UNESCO, 1965. International charter for the conservation and restoration of Monuments and Sites (The Venice Charter), in: 2nd International Congress of Architects and Technicians of Historic Monuments. May 25-31.

Yastikli, N., 2007. Documentation of cultural heritage using digital photogrammetry and laser scanning. Journal of Cultural Heritage (8), pp. 423-427. 